\title{
Allocation Method for Mobile Charging Vehicles Based on the Spatial Charging Demand
}

\author{
Liu Yujun ${ }^{1}$, Yin Hongyuan ${ }^{1}$, Zeng Pingliang ${ }^{2}$, Wang Zhongdong ${ }^{3}$, Lu Zigang ${ }^{3}$ \\ ${ }^{1}$ School of Electrical Engineering, Southeast University, \\ 210096 Nanjing, China \\ ${ }^{2}$ China Electric Power Research Institute, \\ 100192 Nanjing, China \\ ${ }^{3}$ Jiangsu Electric Power Company Research Institute, \\ 211103 Nanjing, China \\ liuyujun@seu.edu.cn
}

\begin{abstract}
At present, the development of electric vehicles (EV) is limited by the lack of charging facilities. While the construction of charging stations is slowing down because of the small ownership of EV and the high operational cost. The mobile charging vehicles (MCV) are proposed to replace the charging station. At first, this paper introduces the MCV's operation architecture. Then the spatial charging demand is estimated based on the travel chain. At last, the allocation method of mobile charging vehicles is studied in detail with the result of estimation result. The simulation result shows that proper number of MCV can replace the function of charging station as well as meet the needs of charging services.
\end{abstract}

Index Terms-Allocation method; Charging demand; Electric vehicles; Travel chain; Meshing map.

\section{INTRODUCTION}

As a new strategic industry, the development of the electric vehicle $(\mathrm{EV})$ is now unstoppable, due to the factors that it can effectively reduce the energy and environment pressure [1]-[3]. However, the progress of the EV is restrained by the lack of charging facilities [4]. Among all of them, the charging station, as a basic charging facility, can directly promote the ownership and development of EV [5], [6] because the energy supply is the most important part of the EV industry and the energy supply pattern is closely related to the development of EV. The draft of the construction planning about the basic charging facilities has been optimistically made by National Energy Administration of China with the result that the production and sales for the new-energy vehicles will be more than five million by 2020 [7]. If 1 vehicle is averagely allocated to 1 slow charger and 0.2 fast charger, there will be 5 million slow chargers and 1 million fast chargers in the future in China [8], [9]. However there are many charging stations has been found to be idle for most of the time which becomes a large waste of investment [10].

Reference [11] suggests to using the mobile charging vehicle (MCV) to replace the charging station. But it did not explain how to allocate the MCV. This paper is dedicated to

Manuscript received d 28 March, 2017; accepted 16 October, 2016.

This research was funded by National Natural Science Foundation of China (No. 51361130152) study on the allocation method of MCV.

\section{Mobile Charging Vehicles}

Centralized charging station can provide power supplies and parking place for MCV while they are not working. Therefore, centralized charging station can be built in the place with low popularity density and abundant land, forming an encirclement outside the city, which would decrease the cost of the construction for charging the MCV. Aiming for the shortest distance between the MCV's working place and the supply station, the idea of Voronoi [11] can be used here to allocate the working range of MCVs that belong to different supply stations, and realize the goal of reducing the power consumption of the moving period.

The MCV possesses the mobility characteristic that can follow the change of the charging demands' spatial temporal distribution. The MCV takes the order predicted by charging station to change the working place or time, meeting the maximization of the users' charging needs.

When receiving the order for the time and place, the worker would drive the MCV to the designated location to provide charging service according to the predicted charging demands.

There should be exclusive parking spaces for MCV in public parking lots. When an EV drives into a parking lot, it has to input the information about whether it needs charging service and the charging capacity, plus with the dwell time and other related information. This information can be used for charge the EVs co-ordinately.

\section{Estimation METHOD FOR SPATIAL CHARGING DEMAND BASED ON THE TRAVEL CHAIN}

Traditional researches for the EV drivers' behaviours merely focus on the separate analysis about the traffic time and space information, and neglect the interaction between this information [12]. The travel chain can depict the sequence of the EV driver's travel activities, presented in a chain form to show different destinations in chronological order [13]. Choosing the travel destination and time is basically simultaneous, thus there is a competing relationship between time and destination. Also, the time and destination of the last travel can affect the next travel plan. 
Typical drivers of the EV usually start a day's travel from home, pass through several spots and go back home at the end of the day. So the typical travel chain of EV is presented in Fig. 1.

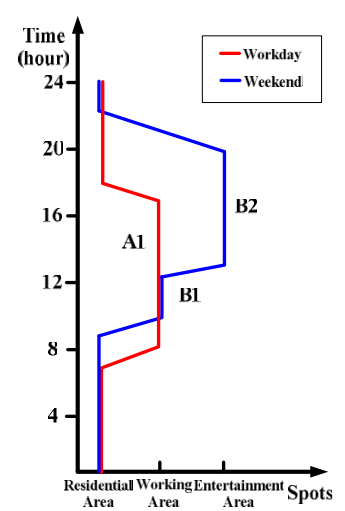

Fig. 1. Typical Travel chain of electric vehicles.

In accordance with the statistic including the travel spot and time for the driver's travel activities within a day by NHTS [14], which divides the spot into residential area (going home or visiting relatives), working area (commuting) and business area (recreation and entertainment). The initial $S O C_{\text {ini }}$ for the $\mathrm{EV}$ is extracted from the travel chain firstly, together with the power capacity $S O C_{\mathrm{dem}}$, needed for this travel. If $S O C_{\mathrm{ini}}-S O C_{\mathrm{dem}}<S O C_{\mathrm{low}}$, (the $S O C_{\mathrm{low}}$ is the lowest threshold of the EV's SOC) it means that this EV has charging demand in the starting point. Assuming that the EV requires full charge of capacity, i.e. $S O C_{\mathrm{ini}}=1$, and if $S O C_{\mathrm{ini}}-$ $S O C_{\mathrm{dem}} \geq S O C_{\mathrm{low}}$, it indicates that there is no need for charging. So $S O C_{\mathrm{ini}}(t+1)=S O C_{\mathrm{ini}}(t)-S O C_{\mathrm{dem}}$ can be obtained until the end of the travel chain. The specific procedure is presented in Fig. 2.

This paper picks BYD-E6 as the EV representative, and the detailed parameters are presented in Table I as follows, supposing that the charging demands appear when the residual energy of the EV taxi is less than the lowest threshold.

TABLE I. PARAMETERS OF A TRADITIONAL ELECTRIC TAXI.
\begin{tabular}{|c|c|c|c|}
\hline $\begin{array}{c}\text { Battery } \\
\text { Capacity }\end{array}$ & $\begin{array}{c}\text { Power } \\
\text { Consumption }\end{array}$ & SOC & $\begin{array}{c}\text { Charging } \\
\text { Time }\end{array}$ \\
\hline $60 \mathrm{kWh}$ & $0.195 \mathrm{kWh} / \mathrm{km}$ & $\mathrm{N}(0.6,0.12)$ & $0.8 \mathrm{~h}$ \\
\hline
\end{tabular}

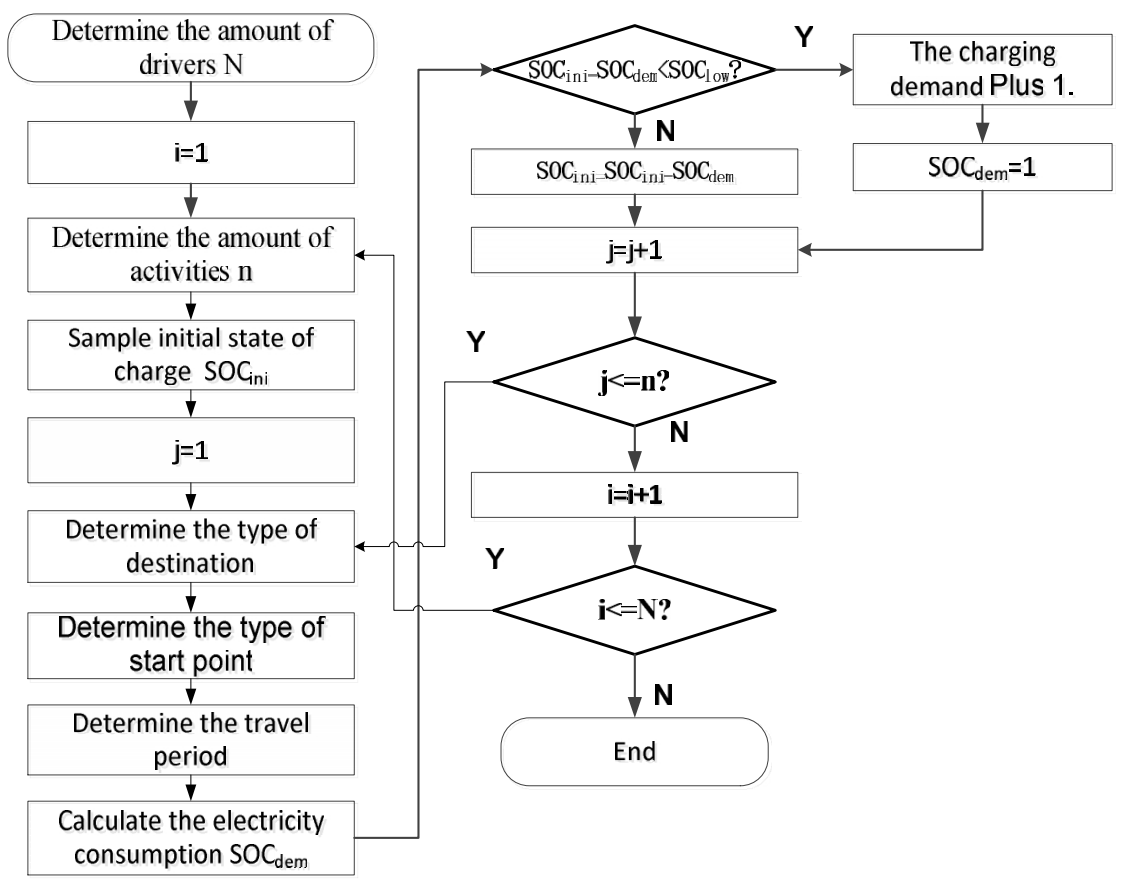

Fig. 2. Flow chart of charging demand forecasting.

\section{Allocation Method For Mobile Charging VEHICLES}

According to the system planning of the MCV's development, the resident plan of the MCV will be studied intensively at first. The mobility advantage of the MCV can be seen directly through the detailed analysis of the mobility characteristic of the MCV.

For the purpose of studying the influence on the traveller's behaviour decision resulted from different traffic information to obtain the detailed spatial distribution characteristic of the charging demand and provide basis of the MCV's resident planning, the actual area of the map is divided into mesh and assigned [15], [16] so as to make distinction between different areas' traffic information. It needs some time for the
EV to pass through the mesh. Given that the population density and activity levels are dissimilar to different area, the function and geographic position of the area are considered in this paper, which means dividing the area based on the typical geographic reference to distinguish the smooth state of the traffic flow in different area. The city will be divided into resident area, working area and business area according to their function. Making the orthogonality between the function and geographic position to study its influence on the population density and activity level will help achieve the research for the effect of the unimpeded state of the EV's traffic flow.

This paper sets the road parameter and function parameter for the functional and geographic attribute of different mesh 
which is represented in (1) and (2). The value can measure the time that the EV spends on passing through this particular area (the discrepancy of the travel time caused by different speed is excluded). The EV can only cross the mesh up, down, left and right but diagonally crossing the mesh. The road parameter for some particular areas with impasse (on account of the buildings, the tourism spots and the rivers) can be set as infinity:

$$
\begin{aligned}
& L_{\mathrm{w}}=\frac{T}{T_{\mathrm{c}}}, \\
& L_{\mathrm{f}}=\frac{T_{1}}{T_{\mathrm{f}}},
\end{aligned}
$$

where $L_{\mathrm{w}}$ represents the road parameter, $L_{\mathrm{f}}$ represents the function parameter, $T$ represents the time for passing through road of one particular area in reality, $T_{\mathrm{c}}$ represents the time for passing through the standard road (no traffic jam plus with normal driving condition), $T_{1}$ represents the time for passing through one particular function area and $T_{\mathrm{f}}$ represents the time for passing through standard function area (no traffic jam plus with normal driving condition).

Taking the Beijing for example, the urban area can be divided into $24 * 32$ meshes, while the urban area is also divided into 5 parts of different roads like the Fifth Ring Road, Fourth Ring Road, Third Ring Road and Second Ring Road. In order to simplify the discussion, the road parameter for 5 different areas is presented in Table II based on the traffic condition in reality. The functions of the resident area, working area and business area are different, making the traffic condition different from each other, and they are presented in Table III. The result combined the road parameter and the function parameter is presented in Fig. 3, and different colours following the sequence of dark blue light blue - light yellow - dark yellow represent the time for passing through particular areas in an increased order.

TABLE II. THE COEFFICIENTS OF ROAD CONDITION

\begin{tabular}{|c|c|}
\hline Region & The Coefficients of Road Condition $\boldsymbol{L}_{\mathbf{w}}$ \\
\hline $1^{\text {st }}$ Ring Road & 2.0 \\
\hline $2^{\text {nd }}$ Ring Road & 1.8 \\
\hline $3^{\text {rd }}$ Ring Road & 1.4 \\
\hline $4^{\text {th }}$ Ring Road & 1.2 \\
\hline $5^{\text {th }}$ Ring Road & 0.8 \\
\hline
\end{tabular}

TABLE III. FUNCTION PARAMETERS.

\begin{tabular}{|c|c|}
\hline Function & Coefficient of Function $\boldsymbol{L}_{\mathbf{f}}$ \\
\hline Resident Area & 1.0 \\
\hline Working Area & 1.2 \\
\hline Business Ares & 1.5 \\
\hline
\end{tabular}

Based on the prediction method of the charging demand in Section III, the Monte Carlo method is used to conduct the sampling for the travelling location, which makes further prediction for the spatial distribution of the charging demand to supply the basis of the MCV's resident plan. Considering the estimation result and the current development of the EV, the prediction period is set as every 8 hours, which means conducting the prediction in 3 different periods of 7:00-15:00, 15:00-23:00 and 23:00-7:00. Due to the less EV on the road at night, the discussion will only be carried out for those EVs with charging demand on 7:00-15:00 and 15:00-23:00. The prediction for the spatial distribution of the charging demand is presented in Fig. 4. Different colours following the sequence of dark blue - light blue - light yellow - dark yellow represent the charging requirement in an increased order.

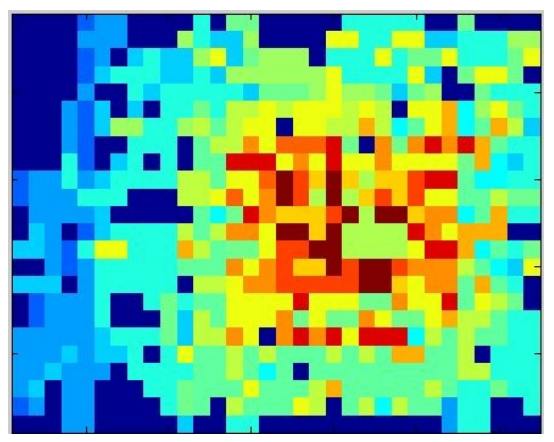

Fig. 3. Meshing Map of Beijing.

The selection principle of the charging facility is selecting the spot of the shortest distance from the EVs as well as meeting the requirement of the charging demand. The objective function is presented in (3)

$$
\min F=\sum_{i \in N} \sum_{j \in M_{i}} d_{i j} a_{i} Z_{i j}
$$

Constrain condition

$$
\sum_{j \in M_{i}} Z_{i j}=1
$$

where $(i \in N)$

$$
Z_{i j} \leq h_{j}
$$

where $\left(i \in N, j \in M_{i}\right)$ :

$$
\begin{gathered}
\sum_{j \in M_{i}} h_{j}=p, \\
Z_{i j}, h_{j} \in\{0,1\},
\end{gathered}
$$

where $\left(i \in N, j \in M_{i}\right)$

$$
d_{i j} \leq s,
$$

here $i$ represents the spot with charging demand, $j$ represents the charging facility, $d_{\mathrm{ij}}$ represents the distance between $i$ and $j, \alpha_{i}$ represents the capacity of the charging demand, $M_{i}$ represents the amount of the spot with charging demand. $Z_{i j}$ is a 0 -1 variable, representing the relationship of distribution of the service demand for the user and the charging facility. If $Z_{i j}$ $=1$, it means that the charging demand of $\operatorname{spot} j$ is provided by charging facility $j$, otherwise $Z_{\mathrm{ij}}=0 . h_{j}$ is a $0-1$ variable, and $h_{j}=1$ means that the spot $j$ is selected as charging facility, otherwise spot $j$ is not selected. $p$ is number of charging facilities, $s$ represents the maximum distance between the demand spot and the charging facility.

As an intelligent optimization algorithm, the immune 
algorithm has favourable ability of seeking the global excellent result, which is suitable for multi-extreme value condition [17]-[19]. In combination with the feature of the immune algorithm, the resident spot and the amount of the MCV are optimized by the immune algorithm, which takes the best service rate and coverage into consideration. The specific selection of the immune algorithm's parameters is presented in Table IV. The result of the MCV's planning optimizing is presented in Fig. 4 and the comparison of results is presented in Table $\mathrm{V}$.

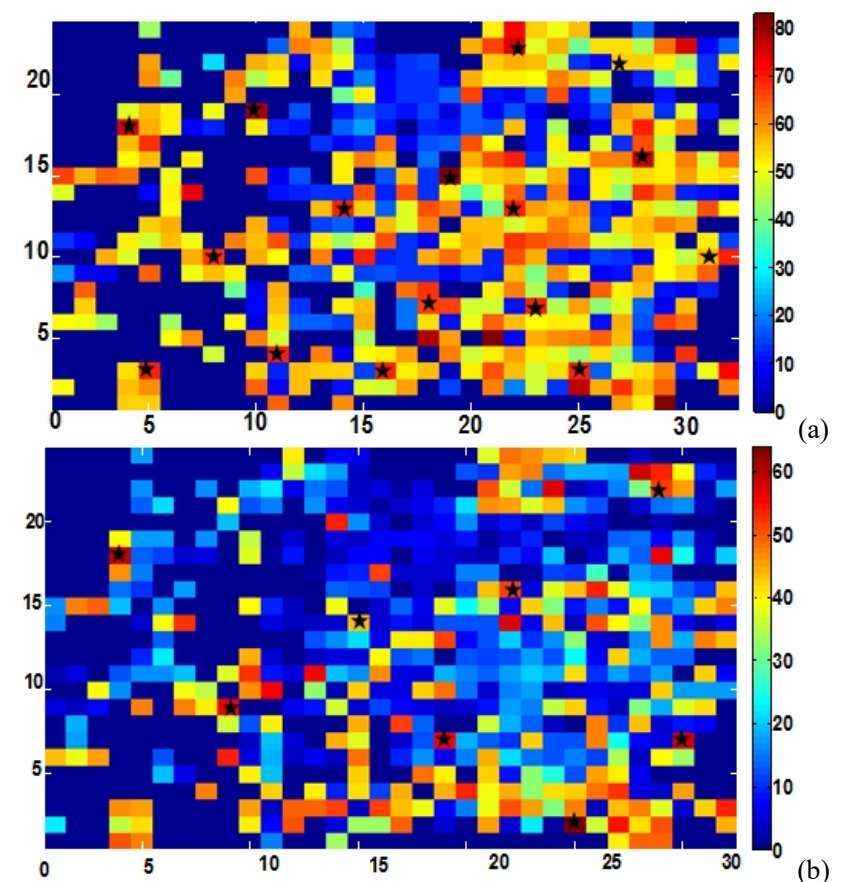

Fig. 4. Spatial charging demand and the planning result: a) 7:00-15:00; b) 15:00-23:00

From 7:00 to 15:00, the service coverage increase from 13 to 17 along with the amount of the MCV. But the fitness does not monotonically raise for that the increase in the MCV might bring the idle MCV, result in the drop of the economic efficiency and affect the outcome of the optimizing. When the amount of the MCV adds up to 15, the increase speed of the coverage is the fastest, but the increasing speed dramatically decreases while the amount of the MCV continues to rise. Another factor influencing the reasonability of the resident plan for MCV is the service rate for the MCV. The coverage will definitely increase in step with the increase of the MCV's amount. Given the purchase and operation cost for the MCV, the economic efficiency will drop if the MCVs in service are not enough. Therefore, the best plan is picked for that $16 \mathrm{MCVs}$ can ensure the fastest increase speed for the coverage. From 15:00 to 23:00, the same method is used to optimize the amount and the location of the MCV. Finally, the best plan is picked for that $8 \mathrm{MCVs}$ can ensure the fastest increase speed for the coverage. Thus, the MCV can all rest and get charged with the power supply station during the night when the charging demand decreases, which dramatically diminishes the operation cost for the MCV and avoids the decrease of the service rate or appearance of the idle MCV. It can be drawn that the MCV pattern has better mobility advantage compared with the charging station pattern.
TABLE IV. PARAMETERS OF IMMUNE ALGORITHM.

\begin{tabular}{|c|c|}
\hline Parameters & Value \\
\hline Population & 30 \\
\hline Capacity of the memory value & 10 \\
\hline Iteration & 1000 \\
\hline Cross over probability & 0.8 \\
\hline Mutation probablility & 0.8 \\
\hline Estimation parameter & 0.95 \\
\hline Amount of the charging facility & 12 \\
\hline
\end{tabular}

TABLE V. COMPARISON BETWEEN DIFFERENT NUMBERS OF STATION.

\begin{tabular}{|c|c|c|c|}
\hline Time & Number of MCV & Fitness & Coverage \\
\hline \multirow{3}{*}{$7: 00-15: 00$} & 17 & $9.07 \mathrm{e}+07$ & $90.03 \%$ \\
\cline { 2 - 4 } & 16 & $6.74 \mathrm{e}+05$ & $81.99 \%$ \\
\cline { 2 - 4 } & 15 & $8.13 \mathrm{e}+06$ & $69.82 \%$ \\
\cline { 2 - 4 } & 14 & $4.68 \mathrm{e}+08$ & $53.94 \%$ \\
\hline \multirow{3}{*}{$15: 00-23: 00$} & 13 & $9.89 \mathrm{e}+09$ & $43.73 \%$ \\
\cline { 2 - 4 } & 10 & $6.73 \mathrm{e}+07$ & $89.98 \%$ \\
\cline { 2 - 4 } & 9 & $4.52 \mathrm{e}+06$ & $84.34 \%$ \\
\hline & 7 & $8.78 \mathrm{e}+05$ & $79.44 \%$ \\
\hline
\end{tabular}

\section{CONCLUSIONS}

In order to encourage more people to accept the idea of the $\mathrm{MCV}$, allocation method is proposed to the MCV. The spatial-temporal distribution of the charging demand is predicted on the basis of the travel chain theory plus with the optimizing of the working time, working place and the amount of the MCV needed for work. During the period of 7:00-15:00 and 15:00-23:00, the best resident plan is made according to the comprehensive optimal choice of the satisfaction rate and the service rate of the MCV, which highlights the mobility advantages of the MCV.

\section{REFERENCES}

[1] F. Wen, F. Wu, Y. Ni, "Generation capacity adequacy in the deregulated electricity market environment", Automation of Electric Power Systems, vol. 26, pp. 16-22, 2002.

[2] A. Shekhar, V. Prasanth, P. Bauer, M. Bolech, "Economic viability study of an on-Road wireless charging system with a generic driving range estimation method", Energies, vol. 9, pp. 941-948, 2016. DOI: https://doi.org/10.3390/en9020076.

[3] M. Brenna, F. Foiadelli, M. Longo, D. Zaninelli, "e-Mobility forecast for the transnational e-Corridor planning", IEEE Trans. Intelligent Transportation Systems, vol. 17, no. 3, pp. 680-689, 2016. DOI: 10.1109/TITS.2015.2480963.

[4] S. Li, Y. Huang, S. J. Mason, "A multi-period optimization model for the deployment of public electric vehicle charging stations on network", Transportation Research Part C: Emerging Technologies, vol. 65, pp. 128-143, 2016. DOI: 10.1016/j.trc.2016.01.008.

[5] Zhipeng Liu, F. Wen, G. Ledwich, "Optimal planning of electric-vehicle charging stations in distribution systems", IEEE Trans. Power Delivery, vol. 28, no. 1, pp. 102-110, 2013. DOI: 10.1109/TPWRD.2012.2223489.

[6] P. Olivella-Rosell, R. Villafafila-Robles, A. Sumper, J. Bergas-Jane, "Probabilistic agent-based model of electric vehicle charging demand to analyse the impact on distribution networks", Energies, vol. 8, no. 5, pp. 4160-4187, 2015. DOI: 10.3390/ en8054160.

[7] J. Wang, K. Wu, Z. Liu, F. Wang, Y. Zhao, "Impact of plug-in hybrid electric vehicles on power distribution networks", in Proc. of 4th International Conference on Electric Utility Deregulation and Restructuring and Power Technologies, 2011, pp. 1618-1622. DOI: 10.1109/DRPT.2011.5994156.

[8] R. C. G. Li, L. Wang, M. Alam, "The impact of plug-in hybrid electric vehicles on distribution networks: A review and outlook", Renew. Sust. Energ. Rev., vol. 15, no. 1, pp. 544-553, 2011. DOI: 10.1016/j.rser.2010.08.015.

[9] M. Majidpour, C. Qiu, P. Chu, H. Pota, R. Gadh, "Forecasting the EV 
charging load based on customer profile or station measurement?", Applied Energy, vol. 163, pp. 134-141, 2016. DOI: 10.1016/j.apenergy.2015.10.184.

[10] J. Zhao, F. Wen, Z. Dong, Y. Xue, K. Wong, "Optimal dispatch of electric vehicles and wind power using enhanced particle swarm optimization", IEEE Trans. Industrial Informatics, vol. 8, no. 4, pp. 889-899, 2012. DOI: 10.1109/ TII.2012.2205398.

[11] Q. Xu, T. Cai, Y. Liu, L. Yao, P. Zeng, "Location planning of charging stations for electric vehicles based on drivers behaviours and travel chain", Automation of Electric Power Systems, vol. 40, pp. 59-65, 2016.

[12] L. Chen, Y. Nie, Q. Zhong, "A model for electric vehicle charging load forecasting based on trip chains", Trans. China Electrotechnical Society, pp. 628-634, 2015.

[13] J. Guo, X. Li, G. Wang, "2016 Beijing transport annual report”, Beijing Transport Institute, Beijing, 2016

[14] Q. Xu, Y. Liu, M. Ding, P. Zeng, W. Pan, "Research on the performance of electric vehicles in peak load shifting", Journal of
Applied Mathematics, vol. 2014, pp. 1-7, 2014. DOI: $10.1155 / 2014 / 957872$.

[15] Q. Yu, X. Han, "Distribution efficiency analysis of battery swapping station considering road cost", Automation of Electric Power Systems, vol. 38, pp. 81-87, 2014.

[16] Y. Weng, Z. Zhu, "Application of geographic information system technique in automation of power system", Automation of Electric Power Systems, vol. 27, pp. 74-78, 2003.

[17] H. Xiong, H. Cheng, H. Li, "Multi-objective reactive power optimization based on immune algorithm", in Proc. CSEE, vol. 26, pp. 102-108, 2006.

[18] H. Yin, T. Liu, F. Li, X. Li, "Distribution network reconfiguration with different distributed generation based on immune genetic algorithm", in Proc. CSU-EPSA, vol. 26, pp. 15-19, 2014.

[19] V. Markevicius, D. Navikas, A. Idzkowski, A. Valinevicius, M. Zilys, D. Andriukaitis, "Vehicle Speed and Length Estimation Using Data from Two Anisotropic Magneto-Resistive (AMR) Sensors", Sensors, vol. 17 , no. 8 , pp. $1-13$, 2017. DOI: $10.3390 / \mathrm{s} 17081778$. 